\title{
Comparison of Primer-Probe Sets among Different Master Mixes for Laboratory Screening of Severe Acute Respiratory Syndrome Coronavirus 2 (SARS-CoV-2)
}

\author{
Hoang Quoc Cuong $\mathbb{D}^{1},{ }^{1}$ Nguyen Duc Hai $\mathbb{D}{ }^{2}$ Hoang Thuy Linh, ${ }^{3}$ Nguyen Hoang Anh, ${ }^{4}$ \\ Nguyen Trung Hieu, ${ }^{4}$ Cao Minh Thang, ${ }^{4}$ Nguyen Thi Thanh Thao, ${ }^{4}$ and Phan Trong Lan ${ }^{1}$ \\ ${ }^{1}$ Directorial board, Pasteur Institute in Ho Chi Minh City, Vietnam \\ ${ }^{2}$ Planning Division, Pasteur Institute in Ho Chi Minh City, Vietnam \\ ${ }^{3}$ Medical Analysis Department, Pasteur Institute in Ho Chi Minh City, Vietnam \\ ${ }^{4}$ Microbiology and Immunology Department, Pasteur Institute in Ho Chi Minh City, Vietnam
}

Correspondence should be addressed to Hoang Quoc Cuong; cuonghqpasteur@gmail.com

Received 13 June 2020; Accepted 13 August 2020; Published 27 September 2020

Academic Editor: György Schneider

Copyright (c) 2020 Hoang Quoc Cuong et al. This is an open access article distributed under the Creative Commons Attribution License, which permits unrestricted use, distribution, and reproduction in any medium, provided the original work is properly cited.

Background. There is a shortage of chemical reagents for severe acute respiratory syndrome coronavirus 2 (SARS-CoV-2) diagnosis and a surge of $S A R S-C o V-2$ cases, especially in limited-resource settings. Therefore, the combination of an optimal assay kit is necessary. Methods. We compared the ability to screen SARS-CoV-2 among three primer-probe sets in two different master mixes, Invitrogen ${ }^{\mathrm{TM}}$ SuperScript ${ }^{\mathrm{TM}}$ III One-Step RT-PCR and LightCycler Multiplex RNA Virus Master. Results. The assay with TIB-Molbiol, IDT, and Phu Sa sets for LightCycler Multiplex RNA Virus Master or Invitrogen ${ }^{\mathrm{TM}}$ SuperScript $^{\mathrm{TM}}$ III One-Step RT-PCR showed positive results from a single reaction of triplicate in the three days of 4.8 copies per reaction. $R$ squared and amplification efficiency were 0.97 and ranged from 107 to $108 \%$, respectively. Conclusions. Our findings indicated that TIB-Molbiol, IDT, and Phu Sa primerprobe sets could be beneficial for the laboratory screening of SARS-CoV-2 by RT-qPCR assay of E gene. There is a need to consider the combination of these reagent sets as a new strategy to increase the testing capacity of screening programs for COVID-19.

\section{Introduction}

Severe acute respiratory syndrome coronavirus 2 (SARS$\mathrm{CoV}-2)$ has a threat to human health which involves over 7,273,958 confirmed cases and 413,372 deaths [1]. While waiting for the coronavirus vaccine approval, molecular testing for SARS-CoV-2 is one of the important strategies to prevent and reduce the rate of infection by case identification, isolation, social distancing, and proper treatment $[2,3]$.

Many factors are leading to the low sensitivity of SARS-CoV-2 such as (a) the detection that depends on the location of clinical specimens, (b) low patient viral load, (c) sporadic shedding, and (d) discrepancy in detection kits from various producers $[4,5]$. However, the molecular diagnosis of SARS-CoV-2 using RT-qPCR assay is a gold standard method [6-8]. Consequently, the combination of an optimal assay kit is necessary because of the shortage of chemical reagents for SARS-CoV-2 diagnosis and the surge of $S A R S-C o V-2$ cases, especially in limited-resource settings.

In the present study, we aim to analyze the commonly used primer-probe sets, targeting E gene of SARS-CoV-2 by the RT-qPCR assay for laboratory screening to increase testing capacity in the context of thousands of overseas travelers returning to their countries.

\section{Materials and Methods}

2.1. Primer-Probe Information. In this study, these three primer-probe sets based on the sequence information received from three different companies, TIB-Molbiol 
(Berlin, Germany), IDT (Integrated DNA Technologies, Skokie, Illinois, USA), and Phu Sa (Phu Sa Biochem, Vietnam), were used for comparative analysis [8] (Supplementary Table 1).

2.2. Viral Preparation. The infection assays were performed in a biosafety level 3 laboratory. Vero E6 cell lines were infected with a clinical isolate $S A R S-C o V-2$ [9]. After 72 hours, the virus medium was inactivated at $65^{\circ} \mathrm{C}$ for 1 hour. Viral RNA was then isolated from the culture medium using the QIAamp viral RNA extraction Kit (Qiagen, Hilden, German) following the manufacturer's instructions. The copy number of RNA extracted from SARS-CoV-2 strain was estimated through a standard curve, which was published in a previous study [10].

SARS-CoV-2 strain isolated in this study is MT192773. The length of the genome sequence was $29,890 \mathrm{bp}$ without gaps and high coverage $1,897 \times$. This strain belonged to Betacoronavirus B type and of $99.98 \%$ sequence similarity at the nucleotide level which was isolated in Wuhan (MT019529) and $>90.56 \%$ similarity with SARS-CoV isolated from pangolin (EPIISL410721). There have been four mutations classified as nonsynonymous mutations such as G8388A (serine to asparagine), A8987T (isoleucine to phenylalanine), and C10232T (arginine to cysteine), and a synonymous mutation is G3778A, which was published in a previous study [9].

2.3. Real-Time Reverse Transcription-Polymerase Chain Reaction (RT-PCR) Assay Confirmation for SARS-CoV-2. RNA-extracted specimens from the inactivated virus were tested for comparative assay of SARS-CoV-2 by RT-qPCR on a LightCycler 480 or ABI 7500 system following the manufacturer's protocol (Invitrogen ${ }^{\mathrm{TM}}$ SuperScript $^{\mathrm{TM}}$ III One-Step RT-PCR System or LightCycler Multiplex RNA Virus Master). In this study, the reaction combination was prepared by multiplying the volumes of each reagent in Table 1 .

RT-qPCR conditions were applied in the present study with details described in Table 2. A cycle threshold value (Ct value) of $\geq 40$ was defined as a negative test [8].

2.4. Analysis. In this study, data were entered using Epi-Data version 3.1 (EpiData Association, Odense, Denmark, 2005), and all statistical analyses were performed using Stata version 13.0 (StataCorp, TX, 2013).

The results were summarized using means and standard deviation (SD) for continuous variables. Linear regression analysis was performed to estimate the $R$ square. Amplification efficiency $(\mathrm{AE})$ was calculated using the equation $\mathrm{AE}=$ $-1+10^{(-1 / \text { slope })}[11]$.

2.5. Ethical Statement. The study protocol has been reviewed and ratified by the Pasteur Institute Ho Chi Minh City Institutional Review Board (reference number: 433/XN-PAS).

\section{Results}

In this study, the assay with TIB-Molbiol, IDT, and Phu Sa sets for LightCycler Multiplex RNA Virus Master showed positive results from a single reaction of triplicate in the three days of 4.8 copies/reaction (Table 3 ).
The Ct values (mean \pm SD) of E gene (TIB-Mobiol), IDT, and $\mathrm{Phu} S \mathrm{Sa}$ at $1: 10^{8} \frac{1}{2}$ were $39.02 \pm 0.34,39.17 \pm 0.34$, and $39.23 \pm 0.10$, respectively. $R^{2}$ value from TIB-Mobiol, IDT, and Phu Sa showed equal values of 0.97. Similarly, the AE of each set was also showing the same value, for the figures of TIB-Mobiol and IDT were 107, and Phu Sa was 108 (Table 4).

The assay with TIB-Molbiol, IDT, and Phu Sa primerprobe sets for the Invitrogen ${ }^{\mathrm{TM}}$ SuperScript $^{\mathrm{TM}}$ III One-Step RT-PCR System exhibited positive results from a single reaction of triplicate in the three days of 4.8 copies/reaction (Table 5). Furthermore, these three primer-probe sets showed the equivalent sensitivity in low concentrations for LightCycler Multiplex RNA Virus Master.

In this study, we found that the $R$-square values from TIB-Molbiol, IDT, and Phu Sa were the same (0.97). Similar to the results of LightCycler Multiplex RNA Virus Master, the AE of IDT and Phu Sa were also the same (108) and 107 for TIB-Molbiol (Table 6).

\section{Discussion}

In this study, we reported the comparative analysis of laboratory screening for SARS-CoV-2 among three primer-probe sets in two different master mixes (Invitrogen ${ }^{\mathrm{TM}}$ SuperScript ${ }^{\mathrm{TM}}$ III One-Step RT-PCR and LightCycler Multiplex RNA Virus Master). The initial analysis showed that the combination of TIB-Molbiol, IDT, and Phu Sa primer-probe sets was quite sensitive to positive results (4.8 copies/reaction) among Invitrogen $^{\mathrm{TM}}$ SuperScript $^{\mathrm{TM}}$ III One-Step RT-PCR System (Table 7). In terms of LightCycler Multiplex RNA Virus Master, TIB-Molbiol, IDT, and Phu Sa primer-probe sets also showed the same sensitivity (4.8 copies/reaction). The $R$ square of each primer-probe set among the different master mixes was around 0.97, and the findings were compatible with a previous study [12]. Also, the values of $\mathrm{AE}$ in each primer-probe set among different master mixes reach the accepted criteria of AE ranged from 90 to $110 \%$ [11]. These findings could also contribute to gain better understandings of the combination of the best reagents for SARS-CoV-2 screening to select the most optimum reagents to effectively halt COVID-19.

The need for the optimum strategies which is aimed at enhancing the testing capacity is a prerequisite because there has been an increasing figure of false-positive results of RTqPCR that were reported in the performances of SARS$\mathrm{CoV}-2$ diagnosis for recovering patients and asymptomatic infected patients [3]. Several recent studies reported the analytical sensitivity and efficiency comparisons of SARS-COV-2 detection by several molecular assays with multiple primerprobe sets [3,12-14]. Although RT-qPCR is appropriate for the large-scale diagnosis of viral infection in normal viral load specimens, the RT-qPCR performance of each primerprobe set is different from others, and various primer-probe sets have contextual amplification with SARS-CoV-2 negative nasopharyngeal swabs [4], resulting in the inconclusive results. Because of the different performances of each primer-probe set in RT-qPCR, the optimization for the design or selection of the proper primer-probe set, the 
TABLE 1: Volumes of reagents for reactions using two different polymerase enzymes combined with three primer-probe sets.

\begin{tabular}{|c|c|c|c|c|c|}
\hline No. & Reagent & $\begin{array}{l}\text { LightCycler Multiplex } \\
\text { RNA Virus Master (TIB- } \\
\text { Molbiol) }\end{array}$ & $\begin{array}{c}\text { LightCycler Multiplex } \\
\text { RNA Virus Master } \\
\text { (IDT/Phu Sa) }\end{array}$ & $\begin{array}{c}\text { Invitrogen }^{\mathrm{TM}} \text { SuperScript }{ }^{\mathrm{TM}} \text { III } \\
\text { One-Step RT-PCR System (TIB- } \\
\text { Molbiol) }\end{array}$ & $\begin{array}{c}\text { Invitrogen }^{\mathrm{TM}} \text { SuperScript }{ }^{\mathrm{TM}} \text { III } \\
\text { One-Step RT-PCR System } \\
\text { (IDT/Phu Sa) }\end{array}$ \\
\hline 1 & $\begin{array}{l}\mathrm{H}_{2} \mathrm{O} \\
\text { (RNAse } \\
\text { free) }\end{array}$ & $10.4 \mu \mathrm{L}$ & $8.4 \mu \mathrm{L}$ & $5.6 \mu \mathrm{L}$ & $3.6 \mu \mathrm{L}$ \\
\hline 2 & $\begin{array}{l}\text { Reaction } \\
\text { mix }\end{array}$ & $4.0 \mu \mathrm{L}$ & $4.0 \mu \mathrm{L}$ & $12.5 \mu \mathrm{L}$ & $12.5 \mu \mathrm{L}$ \\
\hline 3 & $\begin{array}{l}\text { Primer } \mathrm{E}_{-} \\
\text {Sarbeco_ } \\
\quad \text { F1 }\end{array}$ & & $1.0 \mu \mathrm{L}$ & & $1.0 \mu \mathrm{L}$ \\
\hline 4 & $\begin{array}{l}\text { Primer E_ } \\
\text { Sarbeco_ } \\
\quad \text { R2 }\end{array}$ & $0.5 \mu \mathrm{L}$ & $1.0 \mu \mathrm{L}$ & $0.5 \mu \mathrm{L}$ & $1.0 \mu \mathrm{L}$ \\
\hline 5 & $\begin{array}{l}\text { Primer E_ } \\
\text { Sarbeco_ } \\
\quad \text { R2 }\end{array}$ & & $0.5 \mu \mathrm{L}$ & & $0.5 \mu \mathrm{L}$ \\
\hline 6 & $\begin{array}{c}\mathrm{MgSO}_{4} \\
(50 \mathrm{nM})\end{array}$ & $0.4 \mu \mathrm{L}$ & - & $0.4 \mu \mathrm{L}$ & $0.4 \mu \mathrm{L}$ \\
\hline 7 & $\begin{array}{c}\text { RT } \\
\text { enzyme }\end{array}$ & $0.1 \mu \mathrm{L}$ & $0.1 \mu \mathrm{L}$ & $1.0 \mu \mathrm{L}$ & $1.0 \mu \mathrm{L}$ \\
\hline 8 & $\begin{array}{c}\text { Template } \\
\text { RNA }\end{array}$ & $5.0 \mu \mathrm{L}$ & $5.0 \mu \mathrm{L}$ & $5.0 \mu \mathrm{L}$ & $5.0 \mu \mathrm{L}$ \\
\hline & Total & $20 \mu \mathrm{L}$ & $20 \mu \mathrm{L}$ & $25 \mu \mathrm{L}$ & $25 \mu \mathrm{L}$ \\
\hline
\end{tabular}

TABLE 2: RT-qPCR conditions applied in the present study.

\begin{tabular}{lccc}
\hline Parameter & RT step & Denaturation & Cycling \\
\hline Cycles & 1 & 1 & 45 \\
Target temperature $\left({ }^{\circ} \mathrm{C}\right)$ & 55 & 94 & 94 \\
Duration (hours/minutes/seconds) & $00: 10: 00$ & $00: 03: 00$ & $00: 00: 15$ \\
\hline
\end{tabular}

TABLe 3: The results of LightCycler Multiplex RNA Virus Master with three primer-probe sets (IDT, Phu Sa, and TIB-Molbiol).

\begin{tabular}{|c|c|c|c|c|c|c|c|c|c|c|}
\hline \multirow[t]{2}{*}{ Dilution } & \multirow[t]{2}{*}{ Viral copies } & \multicolumn{3}{|c|}{$\begin{array}{l}\text { TIB-Molbiol } \\
\text { Ct values }\end{array}$} & \multicolumn{3}{|c|}{$\begin{array}{c}\text { IDT } \\
\text { Ct values }\end{array}$} & \multicolumn{3}{|c|}{$\begin{array}{c}\text { Phu Sa } \\
\text { Ct values }\end{array}$} \\
\hline & & Day 1 & Day 2 & Day 3 & Day 1 & Day 2 & Day 3 & Day 1 & Day 2 & Day 3 \\
\hline \multirow{3}{*}{$1: 10^{7}$} & \multirow{3}{*}{96} & 34.47 & 34.22 & 35.11 & 34.82 & 34.22 & 35.18 & 34.51 & 34.91 & 34.93 \\
\hline & & 33.87 & 34.38 & 35.30 & 35.28 & 34.66 & 34.53 & 34.62 & 34.67 & 34.63 \\
\hline & & 34.50 & 34.75 & 35.14 & 35.25 & 34.49 & 34.85 & 35.12 & 34.74 & 34.85 \\
\hline \multirow{3}{*}{$1: 10^{71 / 2}$} & \multirow{3}{*}{48} & 36.03 & 36.64 & 36.25 & 36.16 & 36.68 & 35.72 & 36.13 & 36.43 & 36.12 \\
\hline & & 36.81 & 35.35 & 35.87 & 36.32 & 35.97 & 36.35 & 36.62 & 36.17 & 36.35 \\
\hline & & 35.72 & 35.87 & 36.61 & 36.78 & 36.13 & 36.76 & 36.45 & 36.24 & 36.01 \\
\hline \multirow{3}{*}{$1: 10^{8}$} & \multirow{3}{*}{9.6} & 38.30 & 38.11 & 37.47 & 37.49 & 37.85 & 38.25 & 37.92 & 37.51 & 37.75 \\
\hline & & 36.87 & 38.14 & 37.38 & 37.82 & 38.28 & 37.22 & 37.63 & 37.93 & 38.22 \\
\hline & & 37.22 & 37.5 & 37.75 & 37.66 & 37.53 & 38.18 & 37.84 & 37.67 & 37.62 \\
\hline \multirow{3}{*}{$1: 10^{8} \frac{1}{2}$} & \multirow{3}{*}{4.8} & 39.25 & 38.37 & 39.03 & 39.35 & 39.58 & 39.24 & 39.12 & 39.24 & 39.21 \\
\hline & & 38.88 & 38.72 & 38.97 & 39.16 & 39.03 & 38.62 & 39.13 & 39.15 & 39.32 \\
\hline & & 39.24 & 39.50 & 39.21 & 39.25 & 38.99 & 39.28 & 39.17 & 39.33 & 39.41 \\
\hline Negative control & & - & - & - & - & - & - & - & - & - \\
\hline Positive control & & 22.33 & 25.31 & 25.60 & 30.0 & 25.4 & 28.18 & 26.37 & 29.48 & 26.37 \\
\hline
\end{tabular}

“-”: undetected. 
TABle 4: Comparison of Ct value means for LightCycler Multiplex RNA Virus Master with three primer-probe sets (IDT, Phu Sa, and TIBMolbiol).

\begin{tabular}{|c|c|c|c|c|c|c|c|c|c|c|c|c|c|}
\hline \multirow[t]{2}{*}{ Dilution } & \multirow[t]{2}{*}{ Viral copies } & \multicolumn{4}{|c|}{$\begin{array}{l}\text { TIB-Molbiol } \\
\text { Ct values }\end{array}$} & \multicolumn{4}{|c|}{$\begin{array}{c}\text { IDT } \\
\text { Ct values }\end{array}$} & \multicolumn{4}{|c|}{$\begin{array}{l}\text { Phu Sa } \\
\text { Ct values }\end{array}$} \\
\hline & & Mean & $\mathrm{SD}$ & $R^{2}$ & $\mathrm{AE}$ & Mean & SD & $R^{2}$ & $\mathrm{AE}$ & Mean & SD & $R^{2}$ & $\mathrm{AE}$ \\
\hline $1: 10^{7}$ & 96 & 34.64 & 0.47 & \multirow{4}{*}{0.97} & \multirow{4}{*}{107} & 34.81 & 0.37 & \multirow{4}{*}{0.97} & \multirow{4}{*}{107} & 34.78 & 0.19 & \multirow{4}{*}{0.97} & \multirow{4}{*}{108} \\
\hline $1: 10^{7 / 1 / 2}$ & 48 & 36.13 & 0.49 & & & 36.32 & 0.36 & & & 36.28 & 0.20 & & \\
\hline $1: 10^{8}$ & 9.6 & 37.64 & 0.47 & & & 37.81 & 0.37 & & & 37.79 & 0.22 & & \\
\hline $1: 10^{8} \frac{1}{2}$ & 4.8 & 39.02 & 0.34 & & & 39.17 & 0.27 & & & 39.23 & 0.10 & & \\
\hline
\end{tabular}

TABLE 5: The results of Invitrogen ${ }^{\mathrm{TM}}$ SuperScript $^{\mathrm{TM}}$ III One-Step RT-PCR System with three primer-probe sets (IDT, Phu Sa, and TIBMolbiol).

\begin{tabular}{|c|c|c|c|c|c|c|c|c|c|c|}
\hline \multirow[t]{2}{*}{ Dilution } & \multirow[t]{2}{*}{ Copies/reaction } & \multicolumn{3}{|c|}{$\begin{array}{c}\text { TIB-Molbiol } \\
\text { Ct values }\end{array}$} & \multicolumn{3}{|c|}{$\begin{array}{c}\text { IDT } \\
\text { Ct values }\end{array}$} & \multicolumn{3}{|c|}{$\begin{array}{c}\text { Phu Sa } \\
\text { Ct values }\end{array}$} \\
\hline & & Day 1 & Day 2 & Day 3 & Day 1 & Day 2 & Day 3 & Day 1 & Day 2 & Day 3 \\
\hline \multirow{3}{*}{$1: 10^{8}$} & \multirow{3}{*}{96} & 34.23 & 34.51 & 34.81 & 35.07 & 34.91 & 35.03 & 34.34 & 35.21 & 35.31 \\
\hline & & 34.16 & 34.66 & 34.6 & 35.15 & 33.94 & 34.34 & 35.03 & 34.87 & 34.62 \\
\hline & & 34.09 & 34.09 & 34.83 & 35.12 & 34.82 & 34.21 & 34.24 & 34.86 & 35.32 \\
\hline \multirow{3}{*}{$1: 10^{8_{1 / 2}}$} & \multirow{3}{*}{48} & 36.31 & 35.72 & 36.16 & 36.53 & 35.44 & 35.84 & 35.84 & 36.36 & 36.12 \\
\hline & & 35.58 & 35.58 & 36.34 & 36.64 & 36.41 & 36.34 & 36.81 & 36.53 & 35.74 \\
\hline & & 35.69 & 36.00 & 36.14 & 36.58 & 35.71 & 36.66 & 36.71 & 36.34 & 36.83 \\
\hline \multirow{3}{*}{$1: 10^{9}$} & \multirow{3}{*}{9.6} & 37.09 & 37.83 & 37.16 & 36.94 & 37.34 & 37.91 & 37.34 & 38.32 & 38.31 \\
\hline & & 37.23 & 37.09 & 37.71 & 38.03 & 38.07 & 38.15 & 37.86 & 38.21 & 37.87 \\
\hline & & 37.51 & 37.66 & 37.6 & 38.1 & 37.82 & 37.19 & 38.03 & 37.62 & 37.24 \\
\hline \multirow{3}{*}{$1: 10^{9} 1 / 2$} & \multirow{3}{*}{4.8} & 38.59 & 38.59 & 38.66 & 39.62 & 39.32 & 38.82 & 38.82 & 39.72 & 38.74 \\
\hline & & 39.33 & 38.63 & 39.1 & 38.42 & 38.71 & 39.51 & 39.77 & 39.59 & 39.52 \\
\hline & & 39.16 & 39.01 & 39.31 & 39.46 & 39.41 & 39.55 & 39.36 & 39.12 & 39.37 \\
\hline Negative control & & - & - & - & - & - & - & - & - & - \\
\hline Positive control & & 24.27 & 25.91 & 22.81 & 28.40 & 28.38 & 26.72 & 20.81 & 30.56 & 29.39 \\
\hline
\end{tabular}

“-”: undetected.

TABLE 6: Comparison of Ct value means for Invitrogen ${ }^{\mathrm{TM}}$ SuperScript ${ }^{\mathrm{TM}}$ III One-Step RT-PCR System with three primer-probe sets (IDT, Phu Sa, and TIB-Molbiol).

\begin{tabular}{|c|c|c|c|c|c|c|c|c|c|c|c|c|c|}
\hline \multirow[t]{2}{*}{ Dilution } & \multirow[t]{2}{*}{ Viral copies } & \multicolumn{4}{|c|}{$\begin{array}{l}\text { TIB-Molbiol } \\
\text { Ct values }\end{array}$} & \multicolumn{4}{|c|}{$\begin{array}{c}\text { IDT } \\
\text { Ct values }\end{array}$} & \multicolumn{4}{|c|}{$\begin{array}{c}\text { Phu Sa } \\
\text { Ct values }\end{array}$} \\
\hline & & Mean & $\mathrm{SD}$ & $R^{2}$ & $\mathrm{AE}$ & Mean & SD & $R^{2}$ & $\mathrm{AE}$ & Mean & SD & $R^{2}$ & $\mathrm{AE}$ \\
\hline $1: 10^{7}$ & 96 & 34.44 & 0.30 & \multirow{4}{*}{0.97} & \multirow{4}{*}{107} & 34.73 & 0.45 & \multirow{4}{*}{0.97} & \multirow{4}{*}{108} & 34.87 & 0.39 & \multirow{4}{*}{0.97} & \multirow{4}{*}{108} \\
\hline $1: 10^{7 / 1 / 2}$ & 48 & 35.95 & 0.31 & & & 36.24 & 0.44 & & & 36.36 & 0.40 & & \\
\hline $1: 10^{8}$ & 9.6 & 37.43 & 0.29 & & & 37.73 & 0.45 & & & 37.87 & 0.40 & & \\
\hline $1: 10^{8_{1} / 2}$ & 4.8 & 38.93 & 0.30 & & & 39.20 & 0.43 & & & 39.33 & 0.37 & & \\
\hline
\end{tabular}

TABLE 7: Summary of the criteria for three primer-probe sets.

\begin{tabular}{|c|c|c|c|c|c|c|c|c|c|c|c|c|c|}
\hline \multirow{3}{*}{ Dilution } & \multirow{3}{*}{ Viral copies } & \multicolumn{4}{|c|}{$\begin{array}{l}\text { TIB-Molbiol } \\
\text { Ct values }\end{array}$} & \multicolumn{4}{|c|}{$\begin{array}{c}\text { IDT } \\
\text { Ct values }\end{array}$} & \multicolumn{4}{|c|}{$\begin{array}{c}\text { Phu Sa } \\
\text { Ct values }\end{array}$} \\
\hline & & \multicolumn{2}{|c|}{ LightCycler } & \multicolumn{2}{|c|}{ Invitrogen ${ }^{\mathrm{TM}}$} & \multicolumn{2}{|c|}{ LightCycler } & \multicolumn{2}{|c|}{ Invitrogen $^{\mathrm{TM}}$} & \multicolumn{2}{|c|}{ LightCycler } & \multicolumn{2}{|c|}{ Invitrogen $^{\mathrm{TM}}$} \\
\hline & & $R^{2}$ & $\mathrm{AE}$ & $R^{2}$ & $\mathrm{AE}$ & $R^{2}$ & $\mathrm{AE}$ & $R^{2}$ & $\mathrm{AE}$ & $R^{2}$ & $\mathrm{AE}$ & $R^{2}$ & $\mathrm{AE}$ \\
\hline $1: 10^{8}$ & 96 & & & & & & & & & & & & \\
\hline $1: 10^{8_{1} / 2}$ & 48 & & & & & & & & & & & & \\
\hline $1: 10^{9}$ & 9.6 & 0.97 & 107 & 0.97 & 107 & 0.97 & 107 & 0.97 & 108 & 0.97 & 108 & 0.97 & 108 \\
\hline $1: 10^{9} \frac{1}{2}$ & 4.8 & & & & & & & & & & & & \\
\hline
\end{tabular}


appropriate annealing temperature, and the limit of detection for the negative threshold determination could help to eliminate false positives or negatives once designed for clinical diagnosis of viral infection [3].

On the other hand, RT-qPCR assays targeting SARSCoV-2 depended on the high similarity of SARS-CoV-2 to $S A R S-C o V$ as cross-react occurred. Furthermore, there is less sensitivity of the assay when collecting specimens in the early time points after admission [12]. Consequently, almost all laboratories should locally validate diagnostic sensitivities and limit of detection values when beginning these assays [13].

A recent study showed that the droplet digital PCR method could diminish the inaccurate results in the low viral load specimens compared to RT-qPCR [15]. However, the possible false-positive results or false-negative results are arising from the current standard RT-qPCR detection of $S A R S-C o V-2$; therefore, the improved choice of clinical practice could be a comprehensive approach about molecular diagnosis, X-ray or computed tomography scan, and serology test, along with the decision by experienced clinicians in place of exclusively depending on RT-qPCR [15].

Several previous studies have also shown that the selection of the best primer-probe sets and equipment for SARS$\mathrm{CoV}-2$ screening and diagnosis was an urgent and important solution for prevention and control COVID-19 $[12,14]$. Our findings found that these primer-probe sets in two different master mixes were sensitive and reliable for laboratory screening of $S A R S-C o V-2$. Hence, these primer-probe sets could be beneficial for the laboratory screening of SARS$\mathrm{CoV}-2$ by RT-qPCR assay of E gene. It is crucial to improve the capacity of suspected case screenings and to reduce the affected performance of the testing that yield false-negative results [16]. The results of this study are a prelude for other studies to improve the testing capacity of screening suspected cases.

\section{Conclusion}

Our findings indicate that TIB-Molbiol, IDT, and Phu Sa primer-probe sets could be beneficial for the laboratory screening of $S A R S-C o V-2$ by RT-qPCR assay of E gene. There is a need for considering the combination of these reagent sets as a new strategy to increase the testing capacity for screening programs for COVID-19.

\section{Abbreviations}

RT-qPCR: Quantitative reverse transcription PCR

$S A R S-C o V-2$ : Severe acute respiratory syndrome coronavirus 2

COVID-19: Corona virus-infected diseases 19.

\section{Data Availability}

The data used to support the findings of this study are available from the corresponding author upon request.

\section{Conflicts of Interest}

The authors have no conflicts of interest.

\section{Acknowledgments}

We would like to thank colleagues at Pasteur Institute, Ho Chi Minh City for supporting the study. Thanks are due to Mr. Alan Tan, Sydney, Australia, for editing and proofreading the manuscript.

\section{Supplementary Materials}

Supplementary Table: information of primers and probes were used in this study. (Supplementary Materials)

\section{References}

[1] World Health Organization, Coronavirus disease 2019 (COVID19) Situation Report - 97, 2020, https://www.who.int/docs/ default-source/coronaviruse/situation-reports/20200426-sitrep97-covid-19.pdf? sfvrsn=d1c3e800_6.

[2] J. Hellewell, S. Abbott, A. Gimma et al., "Feasibility of Controlling COVID-19 Outbreaks by Isolation of Cases and Contacts," The Lancet Global Health, vol. 8, no. 4, pp. e488-e496, 2020.

[3] C. Zheng, J. Wang, H. Guo et al., "Risk-adapted treatment strategy for COVID-19 patients," International Journal of Infectious Diseases, vol. 94, pp. 74-77, 2020.

[4] D. Toms, J. Li, and H. Y. Cai, Evaluation of WHO listed COVID-19 qPCR primers and probe in silico with 375 SERSCoV-2 full genome sequences, medRxiv, 2020.

[5] A. K. Nalla, A. M. Casto, M. L. W. Huang et al., "Comparative performance of SARS-CoV-2 detection assays using seven different primer/probe sets and one assay kit," Journal of Clinical Microbiology, vol. 58, no. 6, 2020.

[6] C. Drosten, S. Günther, W. Preiser et al., "Identification of a novel coronavirus in patients with severe acute respiratory syndrome," The New England Journal of Medicine, vol. 348, no. 20, pp. 1967-1976, 2003.

[7] L. L. M. Poon, B. W. Y. Wong, K. H. Chan et al., "A one step quantitative RT-PCR for detection of SARS coronavirus with an internal control for PCR inhibitors," Journal of Clinical Virology, vol. 30, no. 3, pp. 214-217, 2004.

[8] V. M. Corman, O. Landt, M. Kaiser et al., "Detection of 2019 novel coronavirus (2019-nCoV) by real-time RT-PCR," Eurosurveillance, vol. 25, no. 3, 2020.

[9] L. T. Phan, T. V. Nguyen, L. K. T. Huynh et al., "Clinical features, isolation, and complete genome sequence of severe acute respiratory syndrome coronavirus 2 from the first two patients in Vietnam," Journal of Medical Virology, vol. 92, no. 10, pp. 2209-2215, 2020.

[10] P. T. Lan, H. Q. Cuong, H. T. Linh et al., "Development of standardized specimens with known concentrations for severe acute respiratory syndrome coronavirus 2 Realtime-RT-PCR testing validation," Bulletin of the World Health Organization, 2020.

[11] J. M. Ruijter, C. Ramakers, W. M. H. Hoogaars et al., “Amplification efficiency: linking baseline and bias in the analysis of quantitative PCR data," Nucleic Acids Research, vol. 37, no. 6, pp. e45-e45, 2009. 
[12] Y. J. Jung, G. S. Park, J. H. Moon et al., Comparative Analysis of Primer-Probe Sets for the Laboratory Confirmation of SARSCoV-2, BioRxiv, 2020.

[13] C. B. Vogels, A. F. Brito, A. L. Wyllie et al., "Analytical sensitivity and efficiency comparisons of SARS-CoV-2 RT-qPCR primer-probe sets," Nature Microbiology, vol. 5, no. 10, pp. 1299-1305, 2020.

[14] A. M. Casto, M. L. Huang, A. Nalla et al., Comparative Performance of SARS-CoV-2 Detection Assays Using Seven Different Primer/Probe Sets and One Assay Kit, medRxiv, 2020.

[15] X. Liu, J. Feng, Q. Zhang et al., "Analytical comparisons of SARS-COV-2 detection by qRT-PCR and ddPCR with multiple primer/probe sets," Emerging Microbes \& Infections, vol. 9, no. 1, pp. 1175-1179, 2020.

[16] R. Stadhouders, S. D. Pas, J. Anber, J. Voermans, T. H. M. Mes, and M. Schutten, "The effect of primer-template mismatches on the detection and quantification of nucleic acids using the 5 ' nuclease assay," The Journal of Molecular Diagnostics, vol. 12, no. 1, pp. 109-117, 2010. 